\title{
CARNAVAL Y SOCIEDAD ANÓMICA COLOMBIANA EN LA CARROZA DE BOLIVARA DE EVELIO ROSERO DIAGO ${ }^{1}$
}

\author{
JORGE VERDUGO PONCE \\ Universidad de Nariño
}

\section{RESUMEN}

Dentro del listado de nuevas novelas históricas colombianas, se publica a comienzos del año 2012 la novela La carroza de Bolívar de Evelio Rosero Diago, escritor de ascendencia nariñense, obra que revela en el sur la compleja realidad de la sociedad colombiana en permanente crisis debido a su fundación a deshora, construida sobre una enorme mentira, la del Bolívar gran militar preocupado por la moralidad pública, y cuyo nefasto ejemplo dado por el "mal llamado Libertador" fundó lo que sería con el tiempo la cultura política colombiana, según la afirmación que hace el doctor Justo Pastor Proceso López, afamado ginecólogo de la ciudad de Pasto, lugar donde se desarrollan los acontecimientos en plena fiesta de carnaval de Blancos y Negros entre el 28 de diciembre de 1966 y hasta el 6 de enero del 67, personaje éste que pretende desarrollar en su vida, por una parte, un proyecto político denunciando, a la manera de Sañudo con sus Estudios sobre la vida de Bolívar, las mentiras dichas sobre Bolívar, y para lo cual patrocinará una carroza con su figura para recordar a la gente del sur su historia pasada, además de su otro proyecto consistente en conseguir el amor de su mujer y el cariño de sus hijas, proyectos que se desarrollarán paralelamente en la historia de la novela, y que terminarán con el asesinato del médico por parte de una célula del ejército de liberación nacional que, a través de su accionar contradictorio, busca limpiar la honra de Bolívar, supuestamente difamada por el protagonista.

La visión carnavalizada del mundo que ofrece el texto y gracias a la cual se permiten algunas libertades que posibilitarán el desarrollo de los proyectos de vida del médico, revelarán la condición de una sociedad anómica generalizada, esto es la existencia de un Estado anómico como lo es el colombiano y, por supuesto, la sociedad del sur del país, regida por una normatividad desprestigiada que contribuye a su desinstitucionalización, y cuyas causas se remontan a los orígenes mismos de fundación de la patria y ante lo cual, recordando el pasado de la región y el cronotopo idílico en el que moraban sus habitantes, se busca recobrar lo perdido, esto es, una forma de vida armoniosa y justa libre de vejámenes y mentiras. Rosero adopta una posición ideológica suprapartidista en su evaluación de la realidad colombiana lo que le permite llevar a cabo su propuesta a través de la verdad de revelación propia del trabajo estético.

Palabras clave: Novela, carnaval, anomia.

1. Este texto se deriva de la tesis doctoral Entre lo idílico y lo pavoroso, cinco novelas de autores de Nariño, presentada para optar al título de Doctor en Literatura de la Universidad de Antioquia. 


\begin{abstract}
Within the list of new colombian historical novels, the novel Bolivar's carriage by Evelio Rosero Diago, writer of Nariño ancestry, is published at the beginning of the year, a work that reveals in the south the complex reality of Colombian society in permanent crisis due to Its founding at once, built on an enormous lie, that of the great military Bolivar concerned with public morality, and whose nefarious example given by the "so-called Liberator"founded what would eventually be the Colombian political culture, according to the statement that Dr. Justo Pastor Proceso López, famous gynecologist of the city of Pasto, where the events take place in the middle of the carnival party of Whites and Blacks between December 28, 1966 and until January 6, 67, a character that Seeks to develop in his life, on the one hand, a political project denouncing, in the manner of Sañudo with his Studies on the life of Bolivar, the lies said about Bolivar, and for which he will sponsor a chariot with his figure to remind people Of the south its past history, in addition to his other project to obtain the love of his wife and the affection of his daughters, projects that will develop parallel in the history of the novel, and that will end with the murder of the doctor on the part of a A cell of the national liberation army that, through its contradictory actions, seeks to clean Bolivar's honor, allegedly defamed by the protagonist.

The carnivalized vision of the world offered by the text and thanks to which certain freedoms are allowed, which will enable the development of the doctor's life projects, will reveal the condition of a generalized anomic society, that is the existence of an anomic State as it is The Colombian and, of course, the society of the south of the country, governed by a discredited normative that contributes to its deinstitutionalization, and whose causes go back to the very origins of foundation of the homeland and before which, remembering the past of the region And the idyllic chronotope in which its inhabitants lived, seeks to recover the lost, that is, a harmonious and just way of life free from vexations and lies. Rosero adopts a supra-party ideological position in his evaluation of the Colombian reality which allows him to carry out his proposal through the truth of revelation proper to the aesthetic work.
\end{abstract}

Key words: Novel, carnival, anomie.

En torno a la conmemoración del Bicentenario de la Independencia de Colombia se han publicado en el país un buen número de novelas cuyo propósito ha sido el de repensar la historia colonial y republicana, la manera como ha sido contada, el accionar de sus protagonistas y las consecuencias de sus actos en la sociedad contemporánea.

Como lo afirma Celia Fernández Prieto en Relaciones pasado-presente en la narrativa histórica contemporánea (1996: 214) "El interés por saber qué pasó se ha desplazado hacia el quién y el cómo lo contó, y hacia el quién, y el cómo lo lee y lo interpreta" destacándose de este modo la importancia del pasado narrado y la posibilidad de debatir las versiones ya contadas, sobre todo aquellas que se adjudican el monopolio de la verdad, todo esto, claro, dentro de las posibilidades que tiene la novela de poner en escena los hechos de la historia y confrontarlos con el imaginario del autor ficcional. Con ello el novelista cumple con la función de "tejer y destejer la memoria colectiva, con las verdades y mentiras de los historiadores y con las ficciones y especulaciones del novelista" (Jorge Eliécer Pardo, 2012:1).

Una de esas novelas es precisamente La carroza de Bolívar del escritor de 
ascendencia nariñense Evelio Rosero Diago, publicada a comienzos del 2012, en la que el protagonista, el afamado ginecólogo de la ciudad de Pasto, el doctor Justo Pastor Proceso López, pretende llevar a cabo en su vida dos proyectos, el primero de carácter político al intentar escribir la auténtica biografía del "nunca tan mal llamado Libertador Simón Bolívar" (Evelio Rosero, 2012: 18), no terminada por cierto, titulada La Gran Mentira de Bolívar o el mal llamado Libertador, cimentada en la obra del historiador nariñense José Rafael Sañudo, el primer historiador "que se atrevió a descifrar de manera irrefutable la catadura histórica de Bolívar, sin falsas emociones patrioteras, sin depender de la corte exagerada de halagos (ojos ciegos y oídos sordos) que la gran mayoría de historiadores concede a Bolívar como una tradición desde su muerte" (59). El doctor Justo pretendía escribir la vida de Bolívar de manera tal que llegara más a un gran público describiendo tanto sus actuaciones políticas, militares y económicas como las de orden humano propósito que, sin embargo, "había resultado demasiado grande para sus fuerzas" (61).

El segundo proyecto correspondía a su drama familiar, a su intento de conseguir el amor de su esposa Primavera Pinzón, el de recuperar el respeto y amor de sus hijas que siempre lo habían despreciado, a él, el doctor Jumento como lo apodaba su mujer, su desamor eterno pero siempre esperanzado.

Aprovechando el inicio del carnaval de Blancos y Negros con el llamado día de Inocentes, el día del baño purificador, en diciembre de 1966, el médico decide disfrazarse de simio para jugar una broma tanto a su familia como a la sociedad, que resulta significativa por cuanto la naturaleza de la festividad le permitía emplear el recurso de la máscara que no encubre ni engaña, como puede ocurrir fuera de la situación en la que está inmiscuido el doctor, sino que, más bien, puede negar con ella, al decir de Bajtin (1974: 42) "la estúpida autoidentificación y coincidencia consigo mismo; la máscara es una expresión de las transferencias, de las metamorfosis, de la violación de las fronteras naturales, de la ridiculización", estableciendo así una relación particular entre la realidad y la propia imagen individual. Justo Pastor bajo el disfraz de simio era otro, esperaba ser más atrayente para su familia aunque no logra en esta oportunidad su acometimiento.

Su otro proyecto, el de escribir la verdad sobre Bolívar, también podría beneficiarse del carnaval y de su apariencia de simio. Al descubrir que los artesanos estaban trabajando en una carroza cuyo tema era la figura de su vecino Arcángel de los Ríos, apodado Furibundo Pita, famoso en la ciudad por perseguir celosamente a su mujer, y que la cara del vecino resultaba idéntica a la de Bolívar, decide convencer a los maestros para que continúen trabajando en ella, patrocinando inclusive la elaboración de la misma, pero en la que aparecerá la figura descomunal del "mal llamado Libertador" desfilando empinado en la carroza el día principal del carnaval de Blancos y Negros, el 6 de enero, levantado en papel maché y rodeado de sus falsas epopeyas, con corona de laurel en la cabeza, sentado en un carromato del siglo XIX tirado por doce niñas como especie de ninfas tal como le gustaban al supuesto héroe.

Esta circunstancia le iba a permitir compartir con los ciudadanos aquello que no había podido hacer hasta el momento con sus escritos, con La Gran Mentira de Bolívar o el mal llamado Libertador. Presentar la carroza era mostrar con ella "nuestra memoria a retazos" (120), en un momento en el que, como 
dice el alcalde Matías Serrano, "ya nadie recuerda en Pasto, Justo Pastor. Los han incorporado eficazmente a la buena historia de Colombia, con toda su retahíla de héroes y ángeles" (121). Pero la figura debía ser un secreto para que pudiera salir en el desfile pues, seguramente, el gobernador, que desconocía quién había sido Agustín Agualongo, que no habría leído a Sañudo y que no pensaba sino que rebuznaba, tomaría medidas al respecto, cosa que efectivamente ocurrió porque a pesar de los cuidados es decomisada por orden del general Lorenzo Aipe, amante de Primavera, disfrazado de Bolívar durante el desfile. La ley no permitía esa afrenta al Libertador, que era lo mismo que una afrenta al país, al Estado, al gobierno de la nación, a su historia.

El hecho es que la festividad del carnaval, como lo dice el doctor Proceso López al disfrazarse de simio, desbarajustaba el orden de las cosas, y aunque el sentido cósmico y la liberación global que propiciaba el carnaval en la Edad Media, el impulso a la subversión que sacaba a la vida de su curso normal, a partir del Renacimiento había empezado a decrecer, a perder ese carácter universal y su importancia en la vida de las gentes empobreciendo sus formas aunque algunas de ellas se conservaran, el "carnaval" había logrado sobrevivir hasta nuestros días aunque, se podría decir, bajo otro régimen y "su sentido emigra de un sistema simbólico a otro", (Bubnova, 2000: 151).

Así, como lo afirma Umberto Eco (1989), "el mundo al revés" que propicia el carnaval ha terminado por convertirse en norma de modo que "la transgresión" resulta aparente y, por consiguiente, tampoco la liberación es tan real como se puede haber supuesto en un primer momento. El carnaval asociado íntimamente a lo cómico requiere de un marco a transgredir presupuesto, es decir no explícito, pero compartido por el emisor y el público y en eso se diferencia de lo trágico y dramático cuyos marcos deben establecerse abiertamente. Entonces, el carnaval parodia los rituales y las reglas pero al mismo tiempo significa que se reconocen esas reglas y rituales de manera que "Sin una ley válida que se pueda romper, es imposible el carnaval" (Eco: 16). Así, la ley está siempre presente en el momento de su violación, en aquel breve momento de la transgresión supuesta que la carnavalización permite disfrutar.

Podemos señalar algunos de los elementos propios del carnaval, como la risa, que en la Edad Media era de carácter ritual, renovadora, que enjuiciaba y relativizaba el poder al mismo tiempo, pero con el debilitamiento de la festividad esa risa va perdiendo su carácter original y en su lugar hoy en día nos encontraríamos, más bien, con el humor, la ironía o el sarcasmo que poco o nada tienen de renovadores. Dice el narrador al comienzo de La carroza que el doctor Justo vivía en una ciudad "que era una sola broma perpetua, donde vivieron y murieron riéndose de sí mismos sus ancestros, en ese país suyo, que también era otra broma atroz pero broma al fin..." (14).

La presencia de animales o héroes animalizados es otro elemento importante en la festividad carnavalesca puesto que contribuye a lograr el efecto cómico de la misma, pero en el caso de la novela de Rosero resulta ambiguo su carácter trágico o cómico y el lector no sabrá si compadecerse o reír del protagonista, o las dos cosas a la vez: él mismo disfrazado de simio y los subversivos que acabarán con su vida disfrazados de burro (símbolo de la estupidez de la autoridad en los estudios de Bajtin) por intentar vengar la afrenta que el médico 
le ha hecho a Bolívar. Los nombres de otros personajes también señalan esa condición animalesca que refuerza la comicidad del relato: Cangrejito Arbeláez o Arcaín Chivo, por ejemplo.

Los apodos como el del obispo conocido como el Avispo, o el gobernador Cántaro llamado el Sapo, Furibundo Pita, el alcalde llamado el Manco de Pasto, etc., también son elementos constitutivos del carnaval, se trata de la positividad del nombre frente a la negatividad del apodo, la memoria frente al olvido. "El nombre se relaciona con lo superior topográfico (está inscrito en los cielos, asociado a la cara del hombre); el apodo se relaciona con lo inferior topográfico... el nombre consagra mientras el apodo profana; el nombre es oficial, el apodo es familiar" (Bajtin, 2000: 195). Propicia el nuevo tipo de relación entre la gente, más cercano, propio de tal festividad. La percepción carnavalesca del mundo involucra también la categoría de la excentricidad estrechamente relacionada con el contacto familiar, y que permite la expresión de aspectos subliminales de la naturaleza humana: en el espacio amplio del carnaval, la ciudad entera en este caso, se observan, entre otras cosas, a un borracho abrazado a un árbol, hablándole, a tres o cuatro monjas tomadas de la mano, dos frailes en el bar de la negra Naranja peleando en un rincón zarandeándose las sotanas, ancianos de 90 años bailando un vals en pleno desfile del 6 de enero que parecían llevar máscaras de cadáveres, los locos del manicomio de San Rafael divirtiéndose también en el desfile, comparsa de presos vestidos de presos que juraron volver a la cárcel cuando acabara el carnaval, y el mismo doctor Proceso López debajo de la ventana del recién fallecido Belencito Jojoa y ante la mirada de los niños extasiándose de amor con Primavera disfrazada de amazona, etc.
Pero ¿cuáles son las tesis que sostienen los supuestos detractores de Bolívar y que aprovechan la oportunidad que les confiere la festividad carnavalesca en la ciudad de Pasto para expresarlas?

Tanto el médico Justo Pastor Proceso López como el escultor en madera Cangrejito Arbeláez y el catedrático Arcaín Chivo sostienen, basados en el libro de Sañudo Estudios sobre la vida de Bolívar, semiotizado por cierto como archivo, que básicamente, "Bolívar dio el desastroso ejemplo que se convertiría con el tiempo en cultura política colombiana" (Rosero: 128): enseñó a la caterva de políticos que le sucedieron a pensar sólo en sí mismos, en el poder; a demorar las prioridades de la nueva república, como la educación, la industria; alargó la guerra tanto cuanto quiso; fue cruel, mal militar "el Napoleón de las retiradas"; racista y traidor, etc. En últimas, la tal independencia del país no ocurrió y quizá no haya ocurrido todavía: "El grito de la independencia era menos que un grito a medias, era un gritito de la nobleza criolla, burgueses que a toda costa querían aprovechar de la tajada. Ninguno pensaba en su pueblo americano y otras lunadas sino en su propia hacienda, señores" (170), les cuenta Arcaín a sus alumnos de la universidad.

Fue, además, Bolívar un "auténtico pionero de la publicidad política colombiana" (203), él mismo dictando folletines sobre su grandiosidad a los extenuados amanuenses que debían inventar su figura de genio.

La masacre de Pasto en diciembre de 1822 se constituyó en el primer ejemplo de barbarie de la historia de Colombia, la primera masacre de todas las que seguirían en el país.

Discutible triunfo en Bomboná, luego del cual inicia una feroz inquina contra los pastusos, "ese infame pueblo", "Haga 
usted prodigios a fin de acabar cuanto antes con los infames de Pasto" (190), le ordena Bolívar a Salom, el peor de sus esbirros.

Por supuesto, estas eran unas tesis que no se podían divulgar como oficiales, eran reprimidas, ocultadas, no se enseñaban, razón por la cual Arcaín Chivo fue expulsado de la universidad y después apaleado por sus acusadores. Pero el carnaval ofrecía la posibilidad de revelar estas verdades bajo la figura alegórica del Bolívar de la carroza. Se acepta la ley pero se la transgrede transitoriamente durante la festividad aunque la represión del estado caiga con todo su peso sobre los infractores.

De hecho en el libro mencionado Estudios sobre la vida de Bolívar, Sañudo inculpa a Bolívar atribuyéndole las siguientes faltas ${ }^{2}$ : Oportunismo, cobardía, traición, realismo, fanfarronería, deserción, imprevisión, irresponsabilidad, venganza, dictadura, incapacidad, indolencia y ambición, cada una de las cuales sustenta con hechos verificables cometidos por Bolívar y debidamente comprobados. Las faltas de su vida privada corresponderán ser expuestas por el doctor Proceso López cuando logre culminar su obra La Gran mentira de Bolivar o el mal llamado Libertador. Las causas históricas de la situación, que conforman un contexto subyacente en la novela, se pueden resumir en los siguientes términos:

Historiadoras como Lydia Inés Muñoz Cordero consideran que, en reali-

2. Sañudo plantea su filosofía de la historia en términos de una teología caracterizada por la ley de la expiación que se debe aplicar a todos los hombres que han influido en la historia, según su moralidad, razón por la cual juzga a Bolívar por su influjo en la guerra de independencia y su ambición al poder, y las consecuencias de ello en el devenir de la patria. Dicha ley ya se había planteado, de hecho, en su novela La expiación de una madre publicada en 1894. dad, "Pasto buscaba su "independencia" a su manera. Necesitaba liberarse de las coyunturas administrativas de Quito y Popayán, para convertirse en una especie de ciudad-estado. Por eso sus reclamos de ser el centro de gobierno, de disponer de autonomía administrativa, legislativa, judicial y eclesiástica, sumado a su expresa solicitud de contar con una Universidad, y ser la sede de la Casa de la Moneda" (1996: 247).

Esto, por supuesto, resultaba en el momento incomprensible pero era la esencia de lo que se ha venido a llamar luego "El realismo Pastuso" como pensamiento político y filosófico, como sistema de ideas que tiene que ver con la existencia cotidiana de un pueblo. La triada rey, religión y patria constituye su base fundamental: el rey como autoridad irremplazable y de origen divino, la religión cristiana como valor social defendible hasta la muerte y la noción de patria en la doble dimensión de Madre Patria (España) y la Patria Local o suelo nutricio más próximo que es el pueblo o la ciudad o el lugar más cercano a las gentes.

En la coyuntura de la guerra de la independencia se prioriza la defensa de la micro-patria, del "solar hogareño" que es "el territorio sagrado para los hombres, mujeres y niños que acuden en masa anónima hacia la ejecución de los distintos planes de resistencia armada, sin importar la no preparación militar, la ausencia de uniformes y de armamento convencional. Los ejidos, los altos, las calles, las viviendas, las iglesias, la parcela en la hora de la guerra, son la patria" (Lydia Inés Muñoz, 1996: 246).

De este modo, lo que se plantea en la novela es que el "Realismo Pastuso" intentaba preservar un modo de vida ancestral de la región fuertemente influenciado por la religión católica y que los movimientos e intromisiones de las 
tropas libertadoras, y aún realistas, lo perturbaron aparentemente para siempre. La nueva República no reparó las consecuencias desastrosas de sus actos y en la conciencia colectiva de los habitantes de la región quedaron recuerdos al respecto, memoria e intentos de recobrar la calma perdida. El mundo idílico ancestral fue destrozado por la naciente república que surgió a destiempo, según lo consideran algunos, y el símbolo de la carroza de Bolívar se convertiría en una luz de esperanza, pues aunque no fue posible que desfilara esta vez, sus artífices, dicen, esperan el carnaval del año siguiente.

El punto siguiente sería preguntarse si habría alternativas para corregir los errores $\mathrm{u}$ horrores de esa sociedad colombiana heredada de Bolívar. La novela plantea la presencia de los grupos subversivos de izquierda en formación, pero su accionar parece, en buena medida, seguir los pasos de Bolívar con todos los defectos que se le han adjudicado: cobardía, traición, fanfarronería, irresponsabilidad, venganza, incapacidad, indolencia, ambición, etc. Los integrantes de la guerrilla, a pesar de ser universitarios, no conocen la historia de la región, ni del país, ni de América, la ignoran: robaron los relieves del escultor Arbeláez, "negro vergajo, artista del enemigo" (265), los mejores, La batalla de Bomboná y El tiempo de los rifles sin conocer su valor y sentido. Justifican las escenas de los fusilamientos: "Bolívar -dice Quiroz- cometió grandes errores... los de un gran hombre: errores necesarios, pero no andaba por ahí confesándolos" (272), o "-Si Bolívar los fusiló, o los sableó, o los picó, fue porque se lo merecían... No se puede poner en tela de juicio a Bolívar" (266). Deben acabar con la vida del doctor Justo Pastor porque, sencillamente, "pretendía burlarse del Libertador Simón Bolívar, padre de la revolución, a través de una carroza de carnaval" (265).
Lo que imperaba en el momento no era más que una gran utopía, el cambio, la revolución que llegaría en pocos meses, máximo en dos años, como les decía Quiroz a sus camaradas, en la que, de todos modos, muchos creían. Pero el dogmatismo no les permitía analizar la situación con lucidez y aunque había urgencia por las transiciones rápidas en las que se transforma "la conciencia individual en "tiempo común" (Ainsa, 2006: 138) siguen anclados al pasado sin saberlo de modo que el futuro continúa a merced del presente que intentan rebasar.

¿Cuál es, entonces, la situación de la región y del país que presenta el mundo ficcional narrativo de la novela de Rosero? Como lo había planteado claramente en su novela anterior, Los ejércitos (2007), lo que se implementa en el país es algo que la narrativa de los últimos años expresa y representa, las circunstancias de desorden social que lejos de ser situaciones excepcionales se han convertido en la norma general de funcionamiento de nuestra sociedad.

La anomia es entendida, en principio, como un estado de anormalidad en una sociedad concreta que busca la recuperación de su equilibrio para volver al orden inicial perdido, pues se trata de situaciones transitorias que afectan a la gente pero ante las cuales el Gobierno tiene la obligación de remediarlas (Durkheim, 1967). Sin embargo, cuando esto no ocurre, cuando la anormalidad es la regla y se convierte la transgresión en nueva normatividad, se está hablando entonces de un Estado Anómico, la expresión es de Peter Waldmann, que trae como consecuencia ausencia de normas consistentes y falta de justicia efectiva, es decir, Estados enteros sin una verdadera consolidación normativa (2003), y "esta situación puede ser paradigmáticamente expuesta en la literatura colombiana" 
(Forero Quintero, 2009: 75). De hecho, en la novela colombiana, "la anomia social se convierte desde este punto de vista en la regla épica de los narradores pues es dentro de ese contexto que se han forjado como tales" (76). Forero se refiere, especialmente, a la llamada novela colombiana de crímenes.

Aunque las situaciones anómicas han sido relativamente frecuentes a lo largo de la historia no lo han sido de la magnitud que se presenta en la novela. En los periodos de crisis las instituciones tradicionales tambalean, las costumbres y valores se modifican, las normas parecen desajustarse con relación a la realidad sobre la que operan y lo establecido, en general, no tiene ya la aceptación acostumbrada de modo que se busca un nuevo equilibrio que restablezca el orden pero éste no alcanza a fijarse con claridad en el grupo social afectado. Toda sociedad, por supuesto, es dinámica y se transforma, pero "la transformación de una sociedad implica la confrontación entre una realidad dada y una realidad deseada, esto es, entre lo que es y lo que debe ser. Y lo que debe ser, está condicionado por las constelaciones de valores que, a su vez, no pueden ser totalmente ajenos a la realidad, pues en todo caso no tendría sentido hablar precisamente de su realización. Los valores no son otra cosa que la realidad en potencia" (Alfredo Verdugo, 1974: 349).

Las normas regulan pero debe haber criterios para su elaboración; entonces, una política legislativa debe tener en cuenta cuando menos los siguientes elementos: valores que se buscan realizar, la realidad social concreta sobre la que se va a actuar, fines precisos que son el resultado de las aspiraciones y la factibilidad en la realidad específica y, también, medios para llevar a cabo esos fines. Las situaciones anómicas, como se puede entender, provienen de varios factores como son la sustitución de las tablas de valores, la transformación radical de situaciones sociales, el abandono de fines previstos y la descompensación entre fines medios. Toda sociedad está conformada por grupos y subgrupos diversos con distintas aspiraciones y valores, eso es inevitable, pero lo que se busca en ella es el logro de un cierto equilibrio que, de todos modos, siempre estará en peligro de romperse.

Si los grupos están bien integrados, los conflictos de normas se solucionan sin mayores dificultades a través de procedimientos establecidos y aceptados. En cambio, cuando esta jerarquía de normas y de autoridad empieza a ponerse en duda, la posibilidad de resolver los conflictos se torna también dudosa. Entonces aparecen los "grupos de presión", con la pretensión de imponerse sobre todo ordenamiento; entonces surgen movimientos diversos que, por distintos medios, buscan satisfacciones no previstas legalmente; entonces diversos grupos empiezan a producir sistemas normativos paralegales en un plano de competencia abierta. Así se produce una situación de ambigüedad normativa que señala lo que podríamos denominar el umbral de la anomia (Alfredo Verdugo, 1974: 351).

Paradójicamente, en situaciones de anomia es cuando más leyes se expiden, por una parte, y dado que padecen el mismo desprestigio que las anteriores tienden a mantenerse sobre la base de la coercitividad, es decir que, por lo general, la autoridad no se debilita y, más bien, ocurre lo contrario: aparece un Estado fuerte que nace de su propia debilidad institucional.

Esta es la situación que se advierte en la novela de Rosero y que se ha ido consolidando en su producción de los últimos años. Se trata de un país cuyo nacimiento o independencia fue a desho- 
ra pues nadie se encontraba preparado, como lo afirma Arcaín Chivo: "un gritito de la nobleza criolla" que se les salió de las manos pues "los miserables de América, indios berracos y campesinos más berracos todavía, que de verdad padecían en carne propia el latigazo perenne desde la conquista, se alborotaron con el gritito, gritaron con fuerza de hombres, se incendió el polvorín, y al igual que Bolívar los señoritos salieron a capitanear una guerra sin ni siquiera saber de estrategia militar, pero ya la intrepidez casi suicida de indios y campesinos los respaldaba, se independizaron de España y después no supieron qué hacer" (Rosero: 171).

Nefasto ejemplo de su primer gobernante: "de Bolívar provienen las pequeñas y grandes dictaduras, y todas estas adversas y corruptas administraciones que los más cínicos han dado en llamar "países en vía de desarrollo"; los indios y campesinos siguen en las mismas, y a su miseria proverbial se suman ahora los obreros de las ciudades" (Rosero: 171). Dos partidos que no se cansan de despojar, abofetear, torturar, sangrar a Colombia, esa fue la suerte que le correspondió al país con la independencia.

Los historiadores, "sarta de medrosos" como los califica el doctor Proceso López, "aparatosos y delirantes", se devanaron los sesos para justificar a Bolívar en sus acciones militares o de estadista. Todos participaron en la elaboración del fraude, "desde los más lúcidos, hasta los más cretinos, excepto Sañudo -finalizóSañudo incomprendido y vilipendiado pero siempre riguroso y avizor, que publicó sus Estudios en 1925" (Rosero: 200).

En esas condiciones, la novela revela, gracias al carnaval, la situación del Estado Anómico que se presenta en Colombia como condición permanente de desorden institucional producido por el gobierno mismo o por la burocracia pública. Su sistema normativo no goza de prestigio, es degradado y, por tanto, al no haber confianza en el Estado surgen normatividades paralelas según los intereses de cada grupo social.

En este estado de cosas el papel de la subversión se aprecia como ineficaz porque como dice Jean Duvignaud "es evidente que el contrario de lo que es no define la subversión, sino el otro elemento complementario del primero en el equilibrio de una estructura" (1990: 34). Entonces, "los contrarios se complementan, pero la subversión destruye los contrarios: la herejía o subversión es de naturaleza distinta a la del sistema en el que se comprenden las oposiciones cómplices entre sí. La subversión, por su parte, aspira a la destrucción del sistema global" (34). El accionar del grupo subversivo de la novela participa de la naturaleza del sistema que pretende combatir, su padre de la revolución es Simón Bolívar, que al igual que conservadores y liberales es objeto de su veneración, y como antes se mencionó, su actuar participa de los vicios del fundador de modo que su actitud transformadora se pone en tela de juicio. Entonces, la futura guerrilla no parece ser en la novela alternativa de cambio alguno y, más bien, le hace el juego al Estado al asesinar al doctor Proceso López y al "revisionista asqueroso" Rodolfo Puelles, el poeta oculto, el que escribía poesía erótica de "humoroso amor", el que leía a Tolstoi, seguramente el más revolucionario de todos los del grupo.

Adicionalmente, el otro proyecto de vida del doctor Proceso López, su intento de lograr el amor de su esposa Primavera refuerza este estado anómico planteado en el universo ficcional de la novela misma. De alguna forma el erotismo del protagonista va a contribuir 
con la constitución del estado anómico de la obra por cuanto, dice Octavio Paz, "Todos los actos eróticos son desvaríos, desarreglos; ninguna ley, material o moral, los determina. Son accidentes, productos fortuitos de combinaciones naturales. Su diversidad misma delata que carecen de significación moral. No podemos condenar unos y aprobar otros mientras no sepamos cuál es su origen y a qué finalidades sirven. La moral, las morales, nada nos dicen sobre el origen real de nuestras pasiones, lo que no les impide legislar sobre ellas, atrevimiento que debería haber bastado para desacreditarlas" (1974: 158).

Los actos eróticos son instintivos y, como tales, sometidos a un complejo sistema de reglas y prohibiciones que intentan canalizarlos pero que, al mismo tiempo, los incitan y los ubican, como todos los actos de los hombres, en la historia. El interdicto inicial del erotismo es, justamente, su prohibición.

El carnaval ha permitido, entonces, la transgresión transitoria de las normas desprestigiadas pero custodiadas celosamente por el Estado, con todo el poder coercitivo del que dispone, revelando impetuosamente la verdadera condición de la realidad colombiana y de la región, la del Estado Anómico, la de la anomia generalizada o, como lo afirma Gustavo Forero, "ese estado de confusión ideológica en la organización social donde resulta imposible que el individuo se reconozca en el contenido de la norma" (2009: 81) pero que resulta difícil de transformar aunque esa sea la aspiración de los protagonistas, habitantes de una región que anhelan llevar a cabo su propia forma de vivir. 


\section{BIBLIOGRAFÍA}

Ainsa, Fernando (2006). Del topos al logos. Propuesta de geopoética. Madrid: Iberoamericana.

Bajtin, Mijail. (1974). La cultura popular en la Edad Media y en el Renacimiento. El contexto de Francois Rabelais. Barcelona: Barral Editores.

(2000). "Adiciones y cambios a Rabelais". En: A.A.V.V. En torno a la cultura popular de la risa.

Barcelona: Anthropos, p.p. 165-218.

Bubnova, Tatiana (2000). "Varia fortuna de la "cultura popular de la risa"'. En: En torno a la cultura popular de la risa. Barcelona: Anthropos.

Duvignaud, Jean. (1990). Herejía y subversión. Ensayos sobre la anomia. Barcelona: Icaria.

Durkheim, Emile (1960). De la división social del trabajo. Buenos Aires: Schapire, S.R.L.

Eco, Umberto (1989). “Los marcos de la "libertad" cómica”. En: ;Carnavali México: F.C.E.

Fernández Prieto, Celia (1996). "Relaciones pasado-presente en la narrativa histórica contemporánea”. En: La novela histórica a finales del siglo XX (Actas del V Seminario Internacional del Instituto de Semiótica Literaria y Teatral de la UNED). Madrid: Visor.

Forero Quintero, Gustavo (2009). "La novela de crímenes en Colombia a partir de la teoría de la anomia: el caso de Comandante Paraíso de Gustavo Álvarez Gardeazábal". En Lingüística y Literatura. Universidad de Antioquia, № 55, pp. 72-85.

Muñoz Cordero, Lydia Inés (1996). "Filosofía del Realismo Pastuso”. En Manual Historia de Pasto. Pasto: Academia Nariñense de Historia, Alcaldía Municipal, pp. 242-249.

Pardo, Jorge Eliécer (2012). "La Carroza de Bolívar de Evelio Rosero. La reencontrada carroza de la novela histórica. Recuperado en internet el 26 de marzo en www.jorgepardoescritor.blogspot.com/2012/03

Paz, Octavio (1974). “El más allá erótico”. En: Los signos en rotación, Barcelona: Círculo de Lectores.

Rosero Diago, Evelio (2012). La carroza de Bolívar. Barcelona: Tusquets.

Sañudo, José Rafael (1995). Estudios sobre la vida de Bolívar. Bogotá: Serie Lista Negra, Editorial Planeta.

Verdugo Villota, Alfredo (1974). "Consideraciones sobre las situaciones anómicas". En Revista de la Academia Colombiana de Jurisprudencia. Bogotá: Nos 204-205, julio-noviembre de 1974, pp. 346-355.

Waldmann, Peter (2003). El Estado Anómico. Derecho, seguridad pública y vida cotidiana en América Latina. Nueva Sociedad. 